\title{
Avaliação quantitativa de fibras colágenas no músculo de frango caipira (Label Rouge e Pedrês)
}

\author{
Yuri Karaccas de Carvalho ${ }^{1 *}$ \\ Luciana dos Santos Medeiros ${ }^{1}$ \\ Kelen Cristiane Zavarize ${ }^{2}$ \\ Henrique Jorge de Freitas ${ }^{1}$ \\ Pedro Primo Bombonato ${ }^{3}$ \\ ${ }^{1}$ Centro de Ciências Biológicas e da Natureza, Universidade Federal do Acre \\ Correios da UFAC, Rodovia BR 364, km 04, Caixa Postal 2030 \\ CEP 69915-900, Rio Branco - AC, Brasil \\ ${ }^{2}$ Escola Superior de Agricultura Luiz de Queiroz, Universidade São Paulo, Piracicaba - SP, Brasil \\ ${ }^{3}$ Departamento de Cirurgia, Faculdade de Medicina Veterinária e Zootecnia \\ Universidade de São Paulo - São Paulo - SP, Brasil \\ *Autor para correspondência \\ ykaracas@yahoo.com.br
}

\section{Resumo}

O objetivo deste estudo foi quantificar as fibras colágenas em diferentes linhagens de frango caipira em diferentes idades e regiões anatômicas. A coleta de material foi realizada em ambas as linhagens (cinco aves/ tratamento) em dois momentos distintos: 42 e 72 dias de idade. Em cada momento foi coletado um fragmento do músculo peitoral torácico (PT) e do músculo iliotibial lateral (ITL), os quais foram fixados em formaldeído a $10 \%$ por 48 horas; eles foram submetidos ao processamento histológico convencional, corados com picrossírius e mensurados por meio do programa de morfometria $K S$ - 400 ZEISS $^{\circledR}$. A quantidade de fibras colágenas presentes nos músculos coletados aos 42 e 72 dias, independente da região estudada, foi, respectivamente, de 2,32 $2,31 \%$ e 4,56 $2,94 \%$, para a linhagem Label Rouge, e 2,26 $1,61 \%$ e 4,92 $2,12 \%$, para a linhagem Pedrês. A quantidade de fibras colágenas nas diferentes linhagens e entre diferentes regiões anatômicas não apresentou diferença estatística significativa. Entretanto, quando a idade (42 e 72 dias) foi considerada, observou-se diferença estatística significativa. $\mathrm{O}$ aumento da quantidade de fibras colágenas presentes nas linhagens estudadas é influenciado pela idade e, possivelmente, é um dos fatores que podem influenciar a textura da carne.

Palavras-chave: Colágeno; Frango caipira; Label Rouge; Músculo; Pedrês

\section{Abstract}

Quantitative evaluation of collagen fibers in country chicken muscle (Label Rouge and Pedres). This study aimed to quantify collagen fibers in different lineages of country chicken at different ages and anatomical regions. The collection of material was carried out in both lineages (five poultries/treatment) at two 
different times: 42 and 72 days of age. At each moment, a fragment of the pectoralis thoracic (PT) and lateral iliotibial (LIT) muscles was collected, which were fixed in 10\% formaldehyde for 48 hours; they underwent a conventional histological approach, they were stained with picrosirius, and they were measured through the morphometry software $K S-400$ ZEISS $^{\circledR}$. The quantity of collagen fibers found in the muscles collected at 42 and 72 days, regardless of the region under study, was, respectively, $2.32 \pm 2.31 \%$ and $4.56 \pm 2.94 \%$, for the Label Rouge lineage, and $2.26 \pm 1.61 \%$ and $4.92 \pm 2.12 \%$, for the Pedres lineage. The quantity of collagen fibers in the different lineages and anatomical regions showed no significant statistical difference. However, when age (42 and 72 days) was taken into account, a significant statistical difference was observed. The increased amount of collagen fibers found in the lineages under study is influenced by age and it's probably one of the factors which can influence meat texture.

Key words: Collagen; Country chicken; Label Rouge; Muscle; Pedres

\section{Introdução}

Com o crescente mercado consumidor de produtos naturais a expansão da chamada avicultura alternativa, a qual consiste na criação de frango e galinha caipira, é um fenômeno mundial (VERCOE et al., 2000). Para que a avicultura alternativa conquiste $o$ mercado consumidor é necessário evidenciar que as aves criadas neste sistema de produção apresentem qualidades semelhantes ou superiores às existentes na avicultura industrial, entre elas a textura da carne (ZANUSSO; DIONELO, 2003).

A textura do músculo é influenciada diretamente pela quantidade de fibras colágenas (LIRA, 1997) e estas variam sua porcentagem na composição muscular de acordo com a idade (NAKAMURA et al., 1975; 2003a; LIRA, 1997), localização e propriedade funcional (TOTLAND et al., 1988; RODRIGUES et al., 1996; SAKAKIBARA et al., 2000). Já para Nakamura et al. (1975), o aumento na quantidade de fibras colágenas também pode ser influenciada diretamente pela idade do animal.

Atualmente, existem estudos que discorrem sobre a quantidade de fibras colágenas presente em músculos de bovinos (FELÍCIO, 1997; HEINEMANN et al., 2003; ALVES et al., 2005, HADLICH et al., 2006; LIMA JUNIOR et al., 2011), suínos (NAKAMURA et al., 2003b) e de aves da avicultura industrial (NAKAMURA et al., 1975; 2004). No entanto, pouco se evidencia sobre a presença de fibras colágenas no músculo de frango caipira em suas diferentes linhagens (TAKAHASHI, 2003).

Devido à pouca informação disponível relacionada à presença de fibras colágenas em frango caipira este estudo pretendeu quantificar estas proteínas nesses animais em diferentes idades. Adicionalmente foram avaliadas as possíveis diferenças na quantidade de fibras colágenas entre linhagens e locais de coleta. A textura do músculo e sua correlação com a quantidade de fibras colágenas encontradas também foi discutida.

\section{Material e Métodos}

O experimento foi conduzido nas instalações experimentais da Universidade Federal do Acre - UFAC. Foram criados 300 pintos de corte, distribuídos em um delineamento experimental randômico, com duas linhagens (Label Rouge e Pedrês), em confinamento, com quinze repetições por tratamento e cada repetição com 10 aves. As rações foram fornecidas na forma farelada à base de fubá de milho e farelo de soja, sendo isentas de promotores de crescimento, antibióticos, anticoccidianos e ingredientes de origem animal, as quais se apresentaram isoenergéticas e isonutritivas.

A coleta de material ocorreu em ambas às linhagens (cinco aves/tratamento) em dois momentos distintos: aos 42 e 72 dias de idade. Em cada momento foi coletado um fragmento do músculo peitoral torácico (PT) e do músculo iliotibial lateral (ITL), os quais foram acondicionados em formaldeído a $10 \%$ por $48 \mathrm{~h}$ e posteriormente mantidos em álcool etílico a $70 \%$.

Em seguida, as amostras foram submetidas ao processamento histológico convencional e incluídos em blocos de parafina para obtenção de cortes de cinco micrometros. Para cada fragmento foram confeccionados duas lâminas com a presença de dois cortes não seriados, 
os quais foram corados por picrossírius. A mensuração ocorreu em cinco campos distintos, com a objetiva de 40X do microscópio Axioscópio ZEISS ${ }^{\circledR}$ acoplado a uma câmera digital. As análises foram feitas com o programa de morfometria KS-400 ZEISS ${ }^{\circledR}$.

Os resultados foram analisados estatisticamente pela análise de variância (ANOVA), e quando necessário às médias foram comparadas utilizando o teste de Tukey com $5,0 \%$ de probabilidade.

\section{Resultados}

A coloração de picrossírius permitiu verificar a presença de fibras colágenas no Músculo Peitoral Torácico (PT) e Músculo Iliotibial Lateral (ITL) nas linhagens Label Rouge e Pedrês em diferentes idades (42 e 72 dias). O colágeno apresentou-se distribuído recobrindo as fibras musculares (endomísio), o conjunto de fibras musculares (perimísio) e o epimísio (Figura 1).
A quantidade de fibras colágenas mostrou-se distribuída igualitariamente entre as três porções de tecido conjuntivo (endomísio, perimísio e epimísio). As fibras colágenas presentes na amostra geral (Média $\pm \mathrm{DV}$ ), independente da região coletada, aos 42 e 72 dias respectivamente, foram de $2,32 \pm 2,31 \%$ e $4,56 \pm 2,94 \%$ para a linhagem Label Rouge e 2,26 $\pm 1,61 \%$ e $4,92 \pm 2,12 \%$ para a linhagem Pedrês.

Em relação aos dois músculos estudados (PT e ILT) não houve diferença estatística entre a quantidade de fibras colágenas tanto na linhagem Label Rouge quanto na Pedrês. Entre as diferentes linhagens de frango, quando comparados grupos de mesma idade, não foi observada diferença estatística na quantidade de fibras colágenas tanto no PT quanto no ILT (Tabela 1).

Ao comparar à quantidade de fibras colágenas aos 42 e 72 dias de idade, entre as duas linhagens e os dois músculos estudados, foi observada diferença significativa, conforme exposto na Tabela 1.

FIGURA 1: Fotomicrografia de corte histológico transversal de musculatura de frango caipira (Label Rouge), evidenciando as fibras colágenas distribuídas no tecido. Endomísio $=$ Seta cheia, Perimísio $=$ Seta pontilhada. Coloração picrossírius. Barra $=50 \mu \mathrm{m}$.

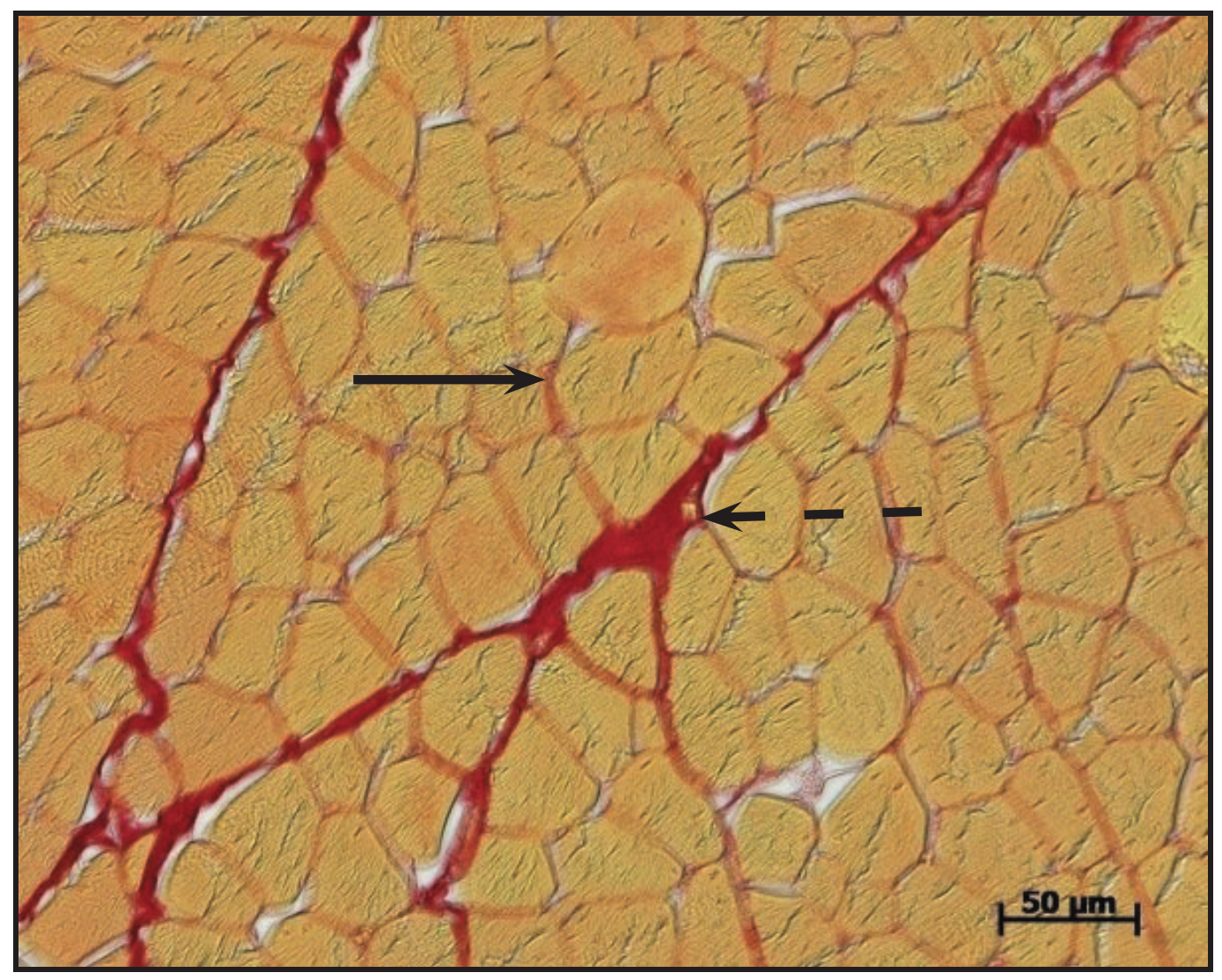


TABELA 1: Valores em porcentagens (Média \pm Desvio Padrão) de fibras colágenas em diferentes linhagens de frango caipira de acordo com o músculo e a idade.

\begin{tabular}{c|c|c|c|c}
\hline Local & \multicolumn{2}{|c|}{$\begin{array}{c}\text { Músculo Peitoral } \\
\text { Torácico (PT) }\end{array}$} & \multicolumn{2}{c}{$\begin{array}{c}\text { Músculo Iliotibial } \\
\text { Lateral (ITL) }\end{array}$} \\
\hline $\begin{array}{c}\text { Idade/ } \\
\text { Linhagem }\end{array}$ & 42 dias & 72 dias & 42 dias & 72 dias \\
\hline $\begin{array}{c}\text { Label } \\
\text { Rouge } \\
\text { Pedrês }\end{array}$ & $2,08 \pm 1,52^{\mathrm{a}}$ & $4,22 \pm 3,17^{\mathrm{a}}$ & $2,44 \pm 2,69^{\mathrm{b}}$ & $5,58 \pm 2,04^{\mathrm{b}}$ \\
\hline
\end{tabular}

$\mathrm{a}, \mathrm{b}, \mathrm{c}, \mathrm{d}=$ Diferença estatística

\section{Discussão}

Após o processamento das amostras deste estudo a quantidade de fibras colágenas presentes nos músculos coletados aos 42 e 72 dias, independente da região

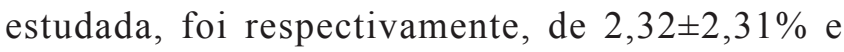
$4,56 \pm 2,94 \%$ para a linhagem Label Rouge e 2,26 $\pm 1,61 \%$ e 4,92 $\pm 2,12 \%$ para a linhagem Pedrês. Satisfatoriamente esses valores assemelham-se a valores encontrados nos animais domésticos, inclusive dos animais utilizados rotineiramente na alimentação humana (BANKS, 1992).

Nishimura et al. (1996), ao pesquisar a quantidade de fibras colágenas em diferentes músculos de bovinos verificaram que o músculo longuíssimo torácico apresentava menor quantidade de fibras colágenas que o músculo semitendinoso. Somado a este fato, em diferentes linhagens de frango industrial foi constatado que a quantidade de fibras colágenas varia no próprio músculo e em diferentes músculos (TOTLAND et al., 1988; RODRIGUES et al., 1996; SAKAKIBARA et al., 2000).

No entanto, em nossos estudos, mesmo tendo sido verificada uma discreta diferença na quantidade de fibras colágenas nos músculos PT e ILT nas diferentes linhagens caipira estudadas, não foi observada diferença estatística. Esses resultados corroboram com estudos de Berri (2000), o qual afirma que músculos distintos podem apresentar a mesma quantidade de fibras colágenas.

O aumento de fibras colágenas para um determinado músculo pode ser induzida por sua propriedade funcional (NISHIMURA et al., 1996), localização anatômica e distribuição desuniforme das fibras colágenas (LEE;
LIN, 1993). Logo é sugerido que os dois músculos estudados nos frangos caipiras, por mais que estejam em regiões distintas, possam ter propriedades funcionais semelhantes, já que não apresentaram diferença estatística na concentração de fibras colágenas.

A quantidade de fibras colágenas na composição muscular varia de acordo com a idade (NAKAMURA et al., 1975; LIRA, 1997). Em ratos e suínos, o avanço da idade promove o aumento da quantidade e arranjo arquitetônico das fibras colágenas (NAKAMURA; OSUGI, 1988; RODRIGUES et al., 1996). Nas amostras analisadas neste estudo observou-se um aumento expressivo na quantidade de fibras colágenas aos $42 \mathrm{e}$ 72 dias de idade nas duas linhagens de frango caipira.

As linhagens Label Rouge e Pedrês não apresentaram diferenças estatísticas nas concentrações de fibras colágenas quando comparados os diferentes grupos musculares. Avaliando este aspecto pode se sugerir que a textura do músculo pode ser semelhante nestas duas linhagens de frango caipira. Entretanto, Lee e Lin (1993), ao compararem galinhas de Taiwan com frangos de corte, tanto nos músculos da coxa quanto do peito das aves, relataram uma quantidade maior de fibras colágenas nas galinhas de Taiwan. Estes resultados indicam que a variação de linhagem e método de criação das aves não pode ser descartada nesse tipo de comparação e que pode influenciar na concentração de fibras colágenas no músculo.

A deposição de colágeno intramuscular influência diretamente na textura da carne (LUCKETT et al., 1975; LIRA, 1997; FANG et al., 1999) e o esperado para frangos caipiras é que apesar da textura diferenciada, quando comparado ao frango de corte industrial, a carne deste apresente uma textura agradável ao paladar do consumidor em geral.

Em nossos estudos observamos que o aumento da quantidade de fibras colágenas presentes nas linhagens estudadas é influenciado pela idade e possivelmente é o fator determinante na textura da carne. Em futuros experimentos, a quantificação de fibras colágenas e sua relação direta com a textura da carne podem ser comparadas entre linhagens caipiras e industriais. 


\section{Referências}

ALVES, D. D.; GOES, R. H. T. B.; MANCIO, A. B. Maciez da carne bovina. Ciência Animal Brasileira, Goiânia, v. 6, n. 3, p. 135-149, 2005.

BANKS, W. J. Histologia Veterinária Aplicada. 2. ed. São Paulo: Manole, 1992, 655 p.

BERRI, C. Variability of sensory and processing qualities of poultry meat. World's Poultry Science Journal, Rotterdam, v. 56, p. 209224, 2000.

FANG, S. H.; NISHIMURA, T; TAKAHASHI, K. Relationship between development of intramuscular connective tissue and toughness of pork during growth of pigs. Journal of Animal Science, Champaign, v. 77, p. 120-130, 1999.

FELICIO, P. E. Fatores que influenciam na qualidade da carne bovina. In: PEIXOTO, A. M.; MOURA, J. C.; FARIA, V. P. (Ed.). Produção de Novilho de Corte. 1 ed. Piracicaba: FEALQ, 1997. p. 79-97.

HADLICH, J. C.; MORALES, D. C.; SILVEIRA, A. C.; OLIVEIRA, H. N.; CHARDULO, L. A. L. Efeito do colágeno na maciez da carne de bovinos de distintos grupos genéticos. Acta Scientiarum Animal Sciences, Maringá, v. 28, n. 1, p. 57-62, 2006.

HEINEMANN, R. J. B.; PINTO, M. F.; ROMANELLI, P. F. Fatores que influenciam a textura da carne de novilhos Nelore e cruzados Limousin-Nelore. Pesquisa Agropecuária Brasileira, Brasília, v. 38, n. 8, p. 963-971, 2003.

LEE, H. F.; LIN, L. C. Studies on the general composition and characteristics of meat quality of the Taiwan country chicken and broiler. Journal of Food Science, Chicago, v. 20, p. 103-111, 1993.

LIMA JUNIOR, D. M.; RANGEL, A. H. N.; URBANO, S. A.; MACIEL, M. V.; AMARO, L. P. A. Alguns aspectos qualitativos da carne bovina: uma revisão. Acta Veterinaria Brasilica, Mossoró, v. 5, n. 4 , p. 351-358, 2011.

LIRA, G. M. Influência do colágeno sobre a textura de carnes. Higiene Alimentar, São Paulo, v. 11, n. 48, p. 12-18, 1997.

LUCKETT, R. L.; BIDNER, T. D.; ICAZA, E. A.; TURNER I. W. Tenderness studies in straighbred and crossbred steers. Journal of Animal Science, Champaign, v. 40, p. 468-475, 1975.

NAKAMURA, F.; OSUGI, T. Age-related changes of intramuscular collagen in rat. Japanese Journal of Zootechnical Science, Tokio, v. 59, p. 997-1003, 1988.

NAKAMURA, R.; SEKOGUCHI, S.; SATO, Y. The contribution of intramuscular collagen to the tenderness of meat from chickens with different ages. Poultry Science, Champaign, v. 54, p. 1604$1612,1975$.
NAKAMURA, Y. N.; IWAMOTO, H.; ONO, Y.; SHIBA, N.; NISHIMURA, S.; TABATA, S. Relationship among collagen amount, distribution and architecture in the $M$. longuissimus toracics and $M$. pectoralis profundus from pigs. Meat Science, Loughborough, v. 64, p. 43-50, $2003 \mathrm{~b}$.

NAKAMURA, Y. N.; IWAMOTO, H.; SHIBA, N.; MIYACHI, H.; TABATA, S.; NISHIMURA, S. Developmental states of the collagen content, distribution and architecture in the pectoralis, iliotibialis lateralis and puboischiofemoralis muscles of male Red Cornish $\times$ New Hampshire and normal broilers. British Poultry Science, Edinburgh, v. 45, n. 1, p. 31-40, 2004.

NAKAMURA, Y. N.; IWAMOTO, H.; TABATA, S.; ONO, Y. Comparison of collagen fibre architecture between slow-twitch cranial and fast-twitch caudal parts of broiler M. latissimus dorsi. British Poultry Science, Edinburgh, v. 44, n. 3, p. 374-379, 2003 a. NISHIMURA, T.; OJIMA, K.; LIU, A.; HATTORI, A.; TAKAHASHI, K. Structural changes in the intramuscular connective tissue during development of bovine semitendinosus muscle. Tissue \& Cell, Siena, v. 28, p. 527-536, 1996.

RODRIGUES, C. J.; RODRIGUES, A. J.; BOHN, G. M. Effects of aging on muscle fibres and collagen content of the diaphragm: a comparison with the rectus abdominais muscle. Gerontology, Los Angeles, v. 42, p. 218-228, 1996.

SAKAKIBARA, K.; TABATA, S.; SHIBA, N.; GOTOH, T.; NISHIMURA, S.; IWAMOTO, H. Myofibre composition and total collagen content in $\mathrm{M}$. iliotibialis lateralis and M. pectoralis of Silkie and White Leghorn chickens. British Poultry Science, Edinburgh, v. 41, p. 570-574, 2000.

TAKAHASHI, S. E. Efeito do sistema de criação sobre o desempenho e qualidade de carne de frangos de corte tipo colonial e industrial. 2003. 64 f. Dissertação (Mestrado em Nutrição e Produção Animal) - Universidade Estadual Paulista, Botucatu. 2003.

TOTLAND, G. K.; KRYVI, H.; SLINDE, E. Composition of muscle fibre types and connective tissue in bovine M. semitendinosus and its relation to tenderness. Meat Science, Loughborough, v. 23, p. 303-315, 1988.

VERCOE, J. E.; FITZHUGH, H. A.; VON KAUFMANN, R. Livestock production systems beyond. Asian-Australasian Journal of Animal Sciences, Seoul, v. 13, n. 5, p. 411-419, 2000.

ZANUSSO, J.; DIONELLO, N. J. L. Produção avícola alternativa - análise dos fatores qualitativos da carne de frangos de corte tipo caipira. Revista Brasileira de Agrociência, Pelotas, v. 9, n. 3, p. 191-194, 2003. 